\title{
Integration of Regenerative Dentistry Into the Dental Undergraduate Curriculum
}

\author{
Hasan Jamal ${ }^{1 *}$ and Mustafa Elhussein ${ }^{2}$ \\ ${ }^{1}$ Department of Paediatric Dentistry, Eastman Dental Institute, University College London, London, United Kingdom, ${ }^{2}$ Faculty \\ of Dentistry, Department of Orthodontics, Ibn Sina University, Khartoum, Sudan
}

Keywords: regenerative dentistry, dental education, dental students, regeneration, molecular biology, genetics, biomaterials

\section{INTRODUCTION}

Rapid scientific advances continue to contribute to novel therapies and technologies, many of which have the potential to transform dentistry. Regenerative medicine can be regarded as a multidisciplinary field encompassing molecular biology, genetics, tissue engineering, and nanotechnology that has been successfully integrated into different clinical disciplines over the last 20 years. Regenerative dentistry focuses on the regeneration of soft and hard tissues by incorporating tissue engineering approaches. It has been defined as "an interdisciplinary field that applies the principles of both engineering and life sciences, toward the development of biological substitutes that restore, maintain, or improve tissue function" (1).

Edited by:

Alastair James Sloan When Will Dentists Be Able to Use Regenerative Therapies?

In dentistry, regenerative therapies are often thought of as a future, rather than a current, modality. However, dentists have been using regenerative therapies for decades, one example being vital pulp therapy. Vital pulp therapy was first introduced in the 17th century, and it relies on the regenerative and reparative capabilities of the tooth (2). More recently, clinicians have used other regenerative approaches. For instance, oral surgeons, periodontists, and implantologists have used bone grafting and guided tissue regeneration (GTR) therapies, well-validated techniques that use biocompatible scaffolds to aid tissue regeneration, for many years (3). Moreover, although less wellevidenced, regenerative endodontic therapies, which aim to revitalize the damaged dental pulp, have now to some extent been clinically translated and have been used by many endodontists and pediatric dentists worldwide (4). The application of regenerative therapies still produces fairly unpredictable outcomes; thus, clinicians and researchers are required to keep abreast of advances in evidence-based regenerative materials.

This article was submitted to Regenerative Dentistry, a section of the journal Frontiers in Dental Medicine

Received: 18 August 2020 Accepted: 27 October 2020 Published: 10 November 2020

\section{A Glimpse Into "Whole Tooth Bioengineering"}

Advances in regenerative dentistry research over recent years have seen whole tooth bioengineering and the use of dental stem cells in a wide array of promising therapies. The discovery of how epithelial and mesenchymal cells interact to initiate a cascade of developmental processes to generate whole organs initiated many efforts to exploit these processes. These pioneering innovations include the first bioengineered tooth via embryonic and adult cell recombination, the characterization of dental pulp stem cells (DPSCs), the first bioengineered tooth grown in a rat jaw, to more recent experiments fabricating bi-layered hydrogel tooth buds (5-8). Tooth primordium can be formed by combining both adult and embryonic stem cells from humans and mice. Furthermore, these constructs, when surgically transplanted in edentulous areas in mice, were shown to develop and erupt into fully functional teeth (9-14). Thus, in principle, tooth organ bioengineering is already a reality. 
Humans, like most mammals, are diphyodonts; that is, they only have two sets of teeth (primary and permanent) (15). However, other animals possess an almost an unlimited capacity to regenerating their teeth (polyphyodonty) (15). These animals include, but are not limited to, crocodiles, alligators, a wide variety of fish, and geckos. For instance, sharks have a set of 300 teeth in both jaws that can be replaced 30,000 times during their lifetimes (16). They replace their teeth in a "vending machine-like" or "conveyer beltlike" manner. Erupted teeth have successors, and underneath these successors lie dormant stem cells. Therefore, when one tooth is shed, it is replaced by its successors and the stem cells start differentiating into tooth buds ready to take their place. Shark teeth were first studied in the 18th century (17), which prompted a series of studies to understand the mechanism behind their regenerative potential. Recent studies have demonstrated that specific sets of genes, mainly from hedgehog, $\mathrm{Wnt} / \beta$-catenin, bone-morphogenic protein, and fibroblast growth factor signaling pathways, are responsible for this phenomenon $(18,19)$. These signaling cascades orchestrate the development of the dental lamina which, in return, regenerates the tooth $(18,19)$.

Other studies have focused on crocodiles, which also possess an exceptional capacity to regenerate teeth. In each jaw quadrant, crocodiles have a set of 20 teeth which can be replaced 50 times during their lifetimes (20). As with sharks, specific sets of genes in different signaling pathways have been shown to be central to tooth regeneration $(19,20)$. Humans also possess these genes, although during evolution they have been "switched off." Understanding the function of these genes and the underlying physiological processes might allow their "re-activation" and the potential to regenerate teeth in patients who have lost their teeth due to an underlying condition or aging.

Although the ultimate goal in regenerative dentistry is to regenerate a whole tooth, studies into tooth regeneration also provide other new therapeutic opportunities (21). Some focus on regenerating specific dental tissues such as dentine, pulp tissues, or enamel using either cell-based approaches, scaffold-based approaches, or both (21). One recent example is the demonstration that certain compounds developed for Alzheimer's disease, namely the small molecule GSK-3 inhibitor tideglusib, can activate dentine reparative mechanisms (21). Low concentrations of these molecules were embedded into injectable collagen sponges which, when placed in contact with vital pulp tissues, stimulated intracellular signaling, stem cell differentiation into odontoblasts, and eventually the production of reparative dentine in its former configuration. This is of particular importance since current materials, mainly tricalcium silicate-based cements, replace dentine rather than regenerating it. As noted above, pulp regeneration can be regarded as a regenerative endodontic therapy that has already clinically translated and documented (4). With respect to enamel, the cell that form it, ameloblasts, die after producing it, making enamel rather difficult to regenerate. However, considerable efforts are being made to mimic or regenerate enamel hydroxyapatite crystals either via biologically-inspired materials or cell-based approaches (22-24).
While these are some examples of many aiming to regenerate specific dental tissues, other groups have focused on exploiting the regenerative potential of DPSCs, a highly pluripotent and accessible cell type. These studies have so far primarily focused on neural repair, smooth muscles regeneration, bladder tissue repair, retinal tissue repair, and bone regeneration, to name a few (25-28).

\section{Dentists for 2030-A Call for Change}

Many clinical treatments have emerged from an in-depth understanding of the underlying molecular biology and genetics, so exposing young dentists to these principles is of prime importance. Currently, dental undergraduates are forced to primarily focus on the clinical aspects of dentistry and skills acquisition, which are, of course, very important. However, due to the current rapid pace of innovation and advances in regenerative dentistry, dentists should be exposed to at least its basics at an early stage. Failing to do so will only make it harder for future dentists to catch up.

One of the authors' personal experiences of studying Regenerative Dentistry at King's College London highlight some of the salient issues. All first and second year dental undergraduates are taught basic biology, but later years at dental school mainly focus on the clinical aspects of dentistry, leaving basic science marginalized. Students applying for the Regenerative Dentistry Program are expected to have a moderate understanding of molecular biology, genetics, and biomaterial sciences. Due to the lack of early exposure to these subjects as undergraduates, graduate students enrolled in these postgraduate programs are likely to experience difficulties with the course materials, which eventually hinders their progress and diverts time away from applying knowledge to research. If, however, undergraduate students were provided with sufficient knowledge of the underlying principles of regenerative dentistry, they would have more time to focus on research and innovation.

\section{Are Dentists Only Destined to Be Clinicians?}

Dentists should no longer solely be clinicians, but instead physicians that put the mouth back to where it belongs, in the body. With recent advances in genomics, not least nextgeneration sequencing technologies, new genetic disorders are constantly being added to the literature. There are now over 6,500 known inherited conditions, 700 of which are craniofacial and dental-related syndromes (29). Individuals can now have their genomes sequences for as little as $\$ 300$. These personalized genetic reports provide individuals with data that may predict their predisposition to a specific disease (e.g., cancer or neurodegenerative disease), meaning that patients are becoming more knowledgeable about their own genetic risk factors and will expect answers and clarification from their healthcare providers.

General dentists could be the first to encounter patients with a genetic disease and, if diagnosed correctly, they could offer the ideal referral. Moreover, pediatric dentists are often the first to receive these referrals, since they diagnose and manage a wide range of genetic defects such as amelogenesis imperfecta (AI), dentinogenesis imperfecta, hypodontia, and supernumerary 
teeth, amongst other craniofacial syndromes such as orofacial clefts. AI does not necessarily affect the teeth alone, in some cases also manifesting with enamel-renal syndrome, a rare genetic disease associated with nephrocalcinosis that affects premature infants (30). These conditions can be detrimental to the health of the child and require immediate intervention. Another example is cleidocranial dysplasia, a rare autosomal dominant skeletal syndrome that is apparent at birth and characterized by dental anomalies and bone abnormalities (31). Its characteristics include clavicle aplasia (absence of the clavicles) and late cranial suture closure. Due to insufficient closure of the cranial vault, part of these children's brains are exposed, mandating head protection such as helmets to avoid brain injuries. Since these conditions are associated with dental anomalies, dentists encounter them relatively frequently and could be the first to provide lifesaving advice.

Therefore, dentists may identify numerous genetic diseases as incidental findings. Some genetic defects, if not detected early, could be lethal, so dentists must have a good working knowledge of genetics to be able to diagnose and deal with such cases. The discovery of new mutations will continue to accelerate, and if dentists are not knowledgeable about them they may not be able to detect, diagnose, or manage them.

\section{The Current Status of Regenerative Dentistry Teaching}

Unlike regenerative medicine, regenerative dentistry is a relatively new field, albeit one that has recently gained a lot of attention. Over the past 5 years, postgraduate programs in "Regenerative Dentistry" have been established in five leading institutions worldwide. The first to pioneer the program was King's College London, followed by the University of Sheffield, Trinity College Dublin, the University of Michigan, and Tokyo Medical and Dental University. The proactive integration of these programs into these dental schools indicates how crucial these programs are for future dentists globally.

This has led to and coincided with studies evaluating levels of knowledge about regenerative dentistry in undergraduate dental students. The outcomes commonly assessed in these studies included knowledge about stem cells; sources of knowledge; interest in continuous education; interest in pursuing graduate education in regenerative dentistry; and clinical applications of stem cells (32). A multicenter study of 231 final year dental students reported that the majority of students had a "poor" level of knowledge with respect to stem cells (33). Nevertheless, $80 \%$ of dental students expressed an interest in pursuing continuing education in stem cells and exploring its clinical applications in regenerative dentistry (33). Similarly, another study of a smaller sample of 80 final year dental students found that $70 \%$ were only able to provide a definition of stem cells and that knowledge about the types and clinical applications of stem cells was poor (34). This corroborates findings from a more recent multicenter study that aimed to evaluate the knowledge and clinical applications of regenerative dentistry in dentists, specialist pediatric dentists, and endodontists (35). In this study, despite disparities among participants, the basic level of knowledge was still poor with respect to stem cells and the clinical applications of regenerative dentistry. However, most of these studies were confined to asking the participants to merely provide a definition of stem cells; a classification of stem cells; and the clinical applications of regenerative dentistry.

\section{DISCUSSION AND CONCLUSIONS}

New scientific discoveries are among several factors that influence dental curricula (36). Additionally, individuals are living longer with chronic conditions, and it is anticipated that dentistry will inevitably also need to adopt precision medicine approaches. The presence of individualized and comprehensive multi-omics (e.g., genomics) datasets is paving the way for tailormade dental treatments and patient-centered care.

In 2017, a workshop coinciding with the American Dental Education Association and Association for Dental Education in Europe (ADEE) meeting in London, involving representatives from 27 countries, was run (37). This workshop provided a forum for discussions aiming to review the position of educators and dental students with respect to emerging scientific advances and best science practices in dental education. Several "new ideas" arose as a result of these discussions including regenerative dentistry, bioactive materials, and enhancing a tooth's innate ability to repair itself.

The Commission on Dental Accreditation recommends that "biological science knowledge should be of sufficient depth and scope for graduates to apply advances in modern biology to clinical practice and to integrate new medical knowledge and therapies relevant to oral health care" (36). However, as highlighted above, undergraduate dental students tend to have a low level of knowledge about regenerative dentistry. In light of the many potential clinical applications of regenerative dentistry, this paper highlights that there are deficiencies in current dental curricula that may hinder the progress of dental students in this area.

While dental professionals have increasing opportunities to participate in continuous development courses as a forum for teaching regenerative medicine-based topics, this approach might not be as adequate as a competency-based curriculum. The results of a national questionnaire-based study in the United Kingdom involving final year dental students reported that dental students felt unprepared for the responsibilities of continuous professional development and self-directed learning (38). The dental students also reported that they were not wellprepared to adopt evidence-based approaches to inform their decisions in terms of patient care (39).

The patient-centered oral healthcare approach is increasingly highlighted and discussed in the literature and policy documents $(40,41)$. Notwithstanding this, the ADEE recommends that dental curricula should be formulated and developed on the basis of the patient-centered care domain, amongst others (41). Hence, it is anticipated that dental curricula should cover "the biological processes in the body to a sufficient depth to be able to exploit new emerging biological technologies in clinical practice, especially in regenerative medicine" (41). Thus, a 
systematic approach to undergraduate education on regenerative dentistry is increasingly recommended for dental students. This approach will ensure that graduating dentists acquire the relevant competencies in regenerative-based medicine.

The way in which regenerative dentistry teaching and regenerative dentistry competencies are integrated into undergraduate dental curricula varies between dental schools worldwide $(42,43)$. Thus, it is vital to develop a teaching "model" that covers the knowledge and skills relevant to regenerative competencies in a dedicated regenerative dentistry core curriculum. Accordingly, formulating the competencies to be achieved by dental students prior to graduation in their clinical years is essential, e.g., harvesting and differentiating dental stem cells or participating in clinically translated regenerative treatments to elaborate on pre-defined learning objectives (44). The learning objectives can be phrased to align with the level of competency to be achieved (45). Modern regenerative dentistry-which aims to exploit stem cells and tissue regeneration to replace tissues or indeed whole teeth-is a complex and multidisciplinary science that requires knowledge of molecular biology, genetics, tissue engineering, and nanotechnology. A dedicated lecture series could thus be designed and delivered in the pre-clinical and clinical years either through a standalone subject, namely "Regenerative Dentistry," or as a sub-theme of existing course material, e.g., dental materials, biology, etc. (46).

\section{REFERENCES}

1. Groll J, Boland T, Blunk T, Burdick JA, Cho DW, Dalton PD, et al. Biofabrication: reappraising the definition of an evolving field. Biofabrication. (2016) 8:013001. doi: 10.1088/1758-5090/8/1/013001

2. Castellucci A. A brief history of endodontics. Endodontics Prato, Italy. (2004) $1: 2-5$

3. Wessing B, Lettner S, Zechner W. Guided bone regeneration with collagen membranes and particulate graft materials: a systematic review and meta-analysis. Int J Oral Maxillofac Implants. (2018) 33:87-100. doi: 10.11607/jomi.5461

4. Tong HJ, Rajan S, Bhujel N, Kang J, Duggal M, Nazzal H. Regenerative endodontic therapy in the management of nonvital immature permanent teeth: a systematic review-outcome evaluation and meta-analysis. J Endod. (2017) 43:1453-64. doi: 10.1016/j.joen.2017.04.018

5. Gronthos S, Mankani M, Brahim J, Robey PG, Shi S. Postnatal human dental pulp stem cells (DPSCs) in vitro and in vivo. Proc Natl Acad Sci USA. (2000) 97:13625-30. doi: 10.1073/pnas.240309797

6. Mina M, Kollar EJ. The induction of odontogenesis in non-dental mesenchyme combined with early murine mandibular arch epithelium. Arch Oral Biol. (1987) 32:123-7. doi: 10.1016/0003-9969(87)9 0055-0

7. Volponi AA, Pang Y, Sharpe PT. Stem cell-based biological tooth repair and regeneration. Trends Cell Biol. (2010) 20:715-22. Epub 2010/11/03. doi: $10.1016 /$ j.tcb.2010.09.012

8. Yang L, Angelova Volponi A, Pang Y, Sharpe PT. Mesenchymal cell community effect in whole tooth bioengineering. J Dent Res. (2017) 96:18691. doi: 10.1177/0022034516682001

9. Angelova Volponi A, Kawasaki M, Sharpe P. Adult human gingival epithelial cells as a source for whole-tooth bioengineering. J Dent Res. (2013) 92:329-34. doi: 10.1177/0022034513481041

10. Ikeda E, Morita R, Nakao K, Ishida K, Nakamura T, Takano-Yamamoto $\mathrm{T}$, et al. Fully functional bioengineered tooth replacement as an
Undergraduate dental students' satisfaction and attitudes toward any teaching "model" should also be evaluated with feedback surveys. Research and innovative case-based pedagogical approaches, as highlighted above, could help to fill current evidence gaps to promote and foster changes to curricula $(43,46,47)$. Additionally, longitudinal investigations involving graduate students enrolled in regenerative dentistry programs would be invaluable.

A further challenge that might eventually arise is a lack of funding, faculty, and trained personnel, amongst other factors. Nevertheless, the process of integrating such topics into the undergraduate dental curricula is likely to be slow, which will allow institutions to adapt accordingly (36). In this regard, "dental students, educators or patients are like chameleons adapting to the ever-changing landscape" (47).

\section{AUTHOR CONTRIBUTIONS}

HJ and ME: writing original paper, review, and editing. All authors contributed to the article and approved the submitted version.

\section{ACKNOWLEDGMENTS}

We would like to thank Prof. Paul Sharpe for his valuable support.

organ replacement therapy. Proc Natl Acad Sci. (2009) 106:13475-80. doi: $10.1073 /$ pnas. 0902944106

11. Jamal HA. Tooth organ bioengineering: cell sources and innovative approaches. Dent J (Basel). (2016) 4:18. doi: 10.3390/dj4020018

12. Nakao K, Morita R, Saji Y, Ishida K, Tomita Y, Ogawa M, et al. The development of a bioengineered organ germ method. Nat Methods. (2007) 4:227-30. doi: $10.1038 /$ nmeth 1012

13. Ohazama A, Modino SA, Miletich I, Sharpe PT. Stem-cell-based tissue engineering of murine teeth. J Dent Res. (2004) 83:518-22. doi: $10.1177 / 154405910408300702$

14. Smith EE, Yelick PC. Bioengineering tooth bud constructs using GelMA hydrogel. Odontogenesis. (2019) 1922:139-50. doi: 10.1007/978-1-4939-9012-2_14

15. Tucker AS, Fraser GJ. Evolution and developmental diversity of tooth regeneration. Semin Cell Dev Biol. (2014) 25-26:71-80. doi: $10.1016 /$ j.semcdb.2013.12.013

16. Kent B. Fossil Sharks of the Chesapeake Bay Region. Columbia, MD: Egan Rees \& Boyer, Inc. (1994). p. 145.

17. Owen R. Odontography, or, A Treatise on the Comparative Anatomy of the Teeth, Their Physiological Relations, Mode of Development, and Microscopic Structure, in the Vertebrate Animals. London: Bailliere (1845).

18. Fraser GJ, Standing A, Underwood C, Thiery AP. The dental lamina: an essential structure for perpetual tooth regeneration in sharks. Integr Comp Biol. (2020) 60:644-55. doi: 10.1093/icb/icaa102

19. Rasch LJ, Martin KJ, Cooper RL, Metscher BD, Underwood CJ, Fraser GJ. An ancient dental gene set governs development and continuous regeneration of teeth in sharks. Dev Biol. (2016) 415:347-70. doi: 10.1016/j.ydbio.2016.01.038

20. Ferguson M. The value of the American alligator (Alligator mississippiensis) as a model for research in craniofacial development. J Craniofac Genet Dev Biol. (1981) 1:123-44.

21. Neves VC, Babb R, Chandrasekaran D, Sharpe PT. Promotion of natural tooth repair by small molecule GSK3 antagonists. Sci Rep. (2017) 7:39654. doi: 10.1038/srep39654 
22. Cao Y, Mei ML, Li QL, Lo EC, Chu CH. Agarose hydrogel biomimetic mineralization model for the regeneration of enamel prismlike tissue. ACS Appl Mater Interfaces. (2014) 6:410-20. doi: 10.1021/am4044823

23. Elsharkawy S, Al-Jawad M, Pantano MF, Tejeda-Montes E, Mehta K, Jamal $\mathrm{H}$, et al. Protein disorder-order interplay to guide the growth of hierarchical mineralized structures. Nat Commun. (2018) 9:2145. doi: 10.1038/s41467-018-04319-0

24. Moradian-Oldak J. Protein-mediated enamel mineralization. Front Biosci (Landmark Ed). (2012) 17:1996-2023. doi: 10.2741/4034

25. Jiang $\mathrm{W}$, Wang $\mathrm{D}$, Alraies A, Liu Q, Zhu B, Sloan AJ, et al. WntGSK3 $\beta / \beta$-catenin regulates the differentiation of dental pulp stem cells into bladder smooth muscle cells. Stem Cells Int. (2019) 2019: 8907570. doi: 10.1155/2019/8907570

26. Leyendecker Junior A, Gomes Pinheiro CC, Lazzaretti Fernandes T, Franco Bueno D. The use of human dental pulp stem cells for in vivo bone tissue engineering: a systematic review. J Tissue Eng. (2018) 9:2041731417752766. doi: $10.1177 / 2041731417752766$

27. Mead B, Logan A, Berry M, Leadbeater W, Scheven BA. Concise review: dental pulp stem cells: a novel cell therapy for retinal and central nervous system repair. Stem Cells. (2017) 35:61-7. doi: 10.1002/stem.2398

28. Sakai K, Yamamoto A, Matsubara K, Nakamura S, Naruse M, Yamagata M, et al. Human dental pulp-derived stem cells promote locomotor recovery after complete transection of the rat spinal cord by multiple neuro-regenerative mechanisms. J Clin Invest. (2012) 122:80-90. doi: 10.1172/JCI59251

29. Online Mendelian Inheritance in Man. OMIM Gene Map Statistics. (2020). Available online at: https:/www.omim.org/statistics/geneMap (accessed August 9, 2020).

30. Fu XJ, Nozu K, Goji K, Ikeda K, Kamioka I, Fujita T, et al. Enamel-renal syndrome associated with hypokalaemic metabolic alkalosis and impaired renal concentration: a novel syndrome? Nephrol Dial Transplant. (2006) 21:2959-62. doi: 10.1093/ndt/gfl328

31. Rimoin DL. International nomenclature of constitutional diseases of bone: revision-May, 1977. Birth Defects Orig Artic Ser. (1978) 14(6B):39-45.

32. Epelman I, Murray PE, Garcia-Godoy F, Kuttler S, Namerow KN. A practitioner survey of opinions toward regenerative endodontics. J Endod. (2009) 35:1204-10. doi: 10.1016/j.joen.2009.04.059

33. Bhatt R, Bhatt A, Gurjar D, Dave L. Evaluating awareness on dental pulp stem cells and its applications amongst graduating dental students of ahmedabad and gandhinagar district: a cross-sectional survey. Adv Hum Biol. (2014) 4:54-9.

34. Chagas JLd, Triches TC, Ximenes Filho M, Cordeiro MMR. Knowledge of stem cells among Dentistry undergraduates. RSBO (Online). (2015) 12:368-76.

35. Al-Shahrani M, Al-Qahtani SA, Al-Nefaie M, Al-Enezi G, Al-Nazhan S. Attitude and opinions of general dental practitioners, pedodontists, and endodontists toward regenerative endodontics in the Kingdom of Saudi Arabia. SEJ. (2020) 10:88. doi: 10.4103/sej.sej_88_19
36. Commission on Dental Accreditation. Accreditation Standards for Dental Education Programs. (2020). Available online at: https://www.ada.org/ / media/CODA/Files/2019_pde.pdf?la=en

37. Dragan IF, Dalessandri D, Johnson LA, Tucker A, Walmsley AD. Impact of scientific and technological advances. Eur J Dent Educ. (2018) 22(Suppl. 1):17-20. doi: 10.1111/eje.12342

38. Ali K, Slade A, Kay E, Zahra D, Tredwin C. Preparedness of undergraduate dental students in the United Kingdom: a national study. Br Dent J. (2017) 222:472-7. doi: 10.1038/sj.bdj.2017.272

39. Scambler S, Delgado M, Asimakopoulou K. Defining patient-centred care in dentistry? A systematic review of the dental literature. Br Dent J. (2016) 221:477-84. doi: 10.1038/sj.bdj.2016.777

40. Field JC, Kavadella A, Szep S, Davies JR, DeLap E, Manzanares Cespedes MC. The Graduating European Dentist-Domain III: patient-centred care. Eur J Dent Educ. (2017) 21(Suppl. 1):18-24. doi: 10.1111/eje.12310

41. Grindrod M, Barry S, Albadri S, Nazzal H. How is paediatric dentistry taught? A survey to evaluate undergraduate dental teaching in dental schools in the United Kingdom. Eur J Dent Educ. (2020).

42. Al Raisi H, Dummer P, Vianna M. How is endodontics taught? A survey to evaluate undergraduate endodontic teaching in dental schools within the United Kingdom. Int Endod J. (2019) 52:1077-85. doi: 10.1111/iej.13089

43. Wiggins G, McTighe J. Understanding by Design. Alexandria, VA: ASCD (2005)

44. Anderson LW, Bloom BS. A Taxonomy for Learning, Teaching, and Assessing: A Revision of Bloom's Taxonomy of Educational Objectives. New York, NY: Longman (2001).

45. Crowe A, Dirks C, Wenderoth MP. Biology in bloom: implementing bloom's taxonomy to enhance student learning in biology. CBE Life Sci Educ. (2008) 7:368-81. doi: 10.1187/cbe.08-05-0024

46. Cowpe J, Plasschaert A, Harzer W, Vinkka-Puhakka H, Walmsley AD. Profile and competences for the graduating European dentist-update 2009. Eur J Dent Educ. (2010) 14:193-202. doi: 10.1111/j.1600-0579.2009.00609.x

47. Mattheos N, Stefanovic N, Apse P, Attstrom R, Buchanan J, Brown P, et al. Potential of information technology in dental education. Eur J Dent Educ. (2008) 12(Suppl. 1):85-92. doi: 10.1111/j.1600-0579.2007.00483.x

Conflict of Interest: The authors declare that the research was conducted in the absence of any commercial or financial relationships that could be construed as a potential conflict of interest.

Copyright (c) 2020 Jamal and Elhussein. This is an open-access article distributed under the terms of the Creative Commons Attribution License (CC BY). The use, distribution or reproduction in other forums is permitted, provided the original author(s) and the copyright owner(s) are credited and that the original publication in this journal is cited, in accordance with accepted academic practice. No use, distribution or reproduction is permitted which does not comply with these terms. 